\title{
A Review of Multiple Sclerosis as an Infectious Syndrome
}

\section{Charles W Stratton}

Department of Pathology, Microbiology and Immunology, Vanderbilt University Medical Center, Nashville, TN 37232, USA

*Corresponding author: Charles W Stratton, Department of Pathology, Microbiology and Immunology, Room 4525-TVC, The Vanderbilt Clinic, Vanderbilt University Medical Center, 1301 Medical Center Drive, Nashville, TN 37232, USA, Tel: 615-343-9063; Fax: 615-343-8420; E-mail: charles.stratton@Vanderbilt.Edu

Received date: September 01, 2016; Accepted date: October 26, 2016; Published date: October 31, 2016

Copyright: (@ 2016 Stratton CW. This is an open-access article distributed under the terms of the Creative Commons Attribution License, which permits unrestricted use, distribution, and reproduction in any medium, provided the original author and source are credited.

\begin{abstract}
Multiple sclerosis (MS) is a chronic neuroinflammatory disease of the central nervous system (CNS) that is generally considered to be an autoimmune myelitis of unknown etiology. Epidemiological studies suggest that infection may act as a trigger on a predisposing genetic background. A number of causative agents have been considered. This review will focus on the pathogenesis of MS and link this pathophysiology to infectious agents that have been implicated as possible co-factors. By doing so, MS will be viewed as an infectious syndrome that involves a CNS infection that results in a neurodegenerative process as well as an autoimmune disease. Early detection of infectious triggers could allow appropriate intervention and thus improved outcomes.
\end{abstract}

Keywords: Multiple sclerosis; Pathogenesis; Pathophysiology; Demyelinating disease; Infectious syndrome; Central nervous system toxin; Clostridium perfringens type B; Epstein-Barr virus; Human herpes virus 6; Human endogenous retroviruses; Lyme Borrelia complex; Chlamydophila pneumoniae, Heat shock protein 60

\section{Introduction}

Multiple sclerosis (MS) is a chronic neuroinflammatory disease that is characterized by progressive, inflammatory, and multifocal demyelination of the brain and spinal cord [1-3]. MS affects approximately 2.5 million people worldwide, with women being afflicted twice as frequently as men [4-6]. Importantly, young adults are the primary groups afflicted with MS: the average age of diseases onset is 30 years, with half of these patients requiring a wheelchair within 25 years of their diagnosis [7-9]. The onset and progression of MS in young adults places a considerable economic burden on these patients, their families, as well as on health and social resources [10].

Currently, there are three prevalent theories on the pathogenic mechanisms for MS: autoimmune, degenerative, and infectious [1-3,8,11-13]. This review briefly describes the evidence for each of these three proposed pathogenic mechanisms and will point out that these pathogenic mechanisms are not mutually exclusive. In fact, a cogent argument will be made that all three proposed mechanisms are involved in the pathogenesis of MS. Moreover, this review will reinforce the evolving concept that brain infections may be triggers for the autoimmune encephalitis and neurodegenerative process that is known as MS.

It is useful to begin this review with a description of the development and progression of the demyelinating plaque, which is the pathological hallmark of MS. Demyelinating lesions in the white matter were first described by Charcot in 1848 and were based on the gross pathology findings of hardened translucent discoloured plaques of brain tissue distributed randomly throughout the white matter of the brain [14]. Charcot believed that these areas were caused by an unidentified toxin or pathogen or perhaps by a disturbance of the circulation. Dawson in 1916 described the histopathology of these plaques as consisting of demyelination and gliosis around blood vessels
[15]. Both early $[14,15]$ and contemporary [16] investigators have noted that these plaques often involve the optic nerve and tend to be located in the periventricular white matter as well as in the cerebellum, the brainstem, and the cervical spinal cord of MS patients. Acute active lesions in MS histologically reveal perivascular infiltration of lymphocytes, plasma cells and macrophages [17-20]. Active lesions are recognized over time as progressing $[8,19]$, with continuous breakdown and regeneration of both myelin [21] and oligodendrocytes [22]. Macrophages are present in the active lesion [20] and are currently thought to be engaged in scavenger activity rather than participating in an autoimmune attack on constituents of the myelin sheath [22]. Heterogeneity of MS lesions has been noted with lesions being distinguished as early active, late active, smouldering, inactive and shadow plaques [23-27]. The histological features of plaques appear to vary over time and also display gender and age-specific differences. These findings suggest the possibility that the targets of injury and the mechanisms of demyelination in MS may be different in different disease subgroups, and that the immune response may shift from adaptive to innate [27]. Finally, the acute MS lesion is associated with increased permeability of the blood brain barrier [27]; such increased permeability of the blood brain barrier has been shown to predict the conversion of optic neuritis to multiple sclerosis [28]

Chronic plaques in MS are seen more frequently with progressive MS and have been classified as smouldering, inactive or shadow plaques [24-27]. Inflammation is present in almost every lesion type although the severity decreases with the age of the patient and the duration of disease. In contrast to acute plaques, the blood brain barrier does not display increased permeability with chronic plaques [29]. Lymphoid follicular structures are found in perivascular locations, and plasma cells increase and persist within the central nervous system. Remyelination can be seen in all stages of plaque and is characterized by the presence of newly formed myelin sheaths as well as by oligodendrocyte precursor cells [30]. The transition of plaque from acute active lesions to chronic inactive lesions is characterized by the decrease in inflammation and the gradual disappearance of macrophages and microglia. Astrocytes actively produce glial fibers, resulting in a glial scar. On gross examination of the MS brain, these glial scars are seen as distinctly demarcated, firm 
Page 2 of 8

brownish discolorations and represent the white matter abnormalities that Charcot first noted as "scleroses en plaque" [14].

Although MS typically has been considered a disease of white matter, it has become very clear that gray matter is also involved [31]. Of note is that Charcot in 1877 also described demyelinated lesions in gray matter [32], but these observations were mostly ignored. Histological, immunohistochemical studies, and DIR-based imaging studies clearly demonstrate that cortical gray matter is extensively demyelinated in MS, and that these cortical lesions represent a significant proportion of the pathology of MS [31]. Moreover, the cellular composition of the cortical gray matter lesions is considerably different from that of white matter lesions, suggesting that there is a location-dependent expression of the immunopathological process in MS $[31,33]$. The most extensive cortical damage is located in the cingulate gyrus and the temporal and frontal cortices. In addition, extensive demyelination is also noted in the hippocampus of MS patients. These areas may be particularly susceptible to inflammation and/or neurodegenerative processes [31]. A currently accepted classification of cortical lesions describes Type I lesions as those that extend through both the white matter and the gray matter. Type II lesions are entirely located with the cerebral cortex and do not interact with the subcortical white matter or the pia mater; these lesions, in general, are perivascular small lesions. Type III lesions are subpial areas of demyelination that do not extend beyond layers 3 and 4 of the cortex. Finally, Type IV lesions typically extend over the entire width of the cortex, but do not extend into the subcortical white matter; these Type IV lesions may spread over several gyri or entire lobes [31]. Of note is the difference in the degree and type of inflammatory response between demyelination in white matter versus that in gray matter, with gray matter demyelination having significantly less lymphocytic infiltration than that seen with white matter demyelination. Another difference in the cellular inflammatory response seen in gray matter demyelination is the presence of activated microglial cells in the demyelinated tissue rather than phagocytic macrophages that are typically seen in white matter demyelination $[32,34]$. Finally, in those cortical lesions that do not extend into white matter, there appears to be normal blood-brain barrier function $[32,35]$.

In addition to demyelination of both white and gray matter, it has become clear that the pathogenesis of MS also involves widespread synaptic loss that is independent of demyelination and axonal degeneration in the gray matter of MS brains [36]. Although the exact pathophysiology for this widespread synaptic loss is unclear, one possible explanation is that synapses could be a susceptible target of widespread inflammation [36]. For example, secreted inflammatory mediators such as interferon-gamma [37] and TNF-alpha [38] and/or diffusely activated microglia cells induced by focal activation of the complement cascade [39] may contribute to low-grade, but widespread inflammation that is independent from white and gray matter plaques. This process of low-grade inflammation may be assisted in some MS patients by the presence of B-cell follicle-like structures in the meninges [40].

This brief overview of the pathologic lesions involved in the MS brain strongly suggests that there exists a widespread progressive neurodegenerative disease in which persistent inflammation plays a prominent role. It is very likely that there is an autoimmune component to this persistent inflammation, although specific autoreactive targets have not been well delineated [41] and immunotherapy of MS does not prevent disease progression in a substantial number of patients [42].
Given that both neurodegeneration and autoimmunity appear to be involved in the pathogenesis of MS, what role might infection(s) play? Infections have long been thought to play a role in MS, but that role remains to be clearly defined. The possible roles of infections as triggers for a neurodegenerative process with an autoimmune response in the pathogenesis of MS will be reviewed using examples from the medical literature.

Charcot believed that demyelinated plaques observed in MS brains might be caused by an unidentified toxin. Such a toxin could originate from the GI tract via a colonizing or an infecting microbe. This possibility is nicely illustrated by work done by Rumah et al [42-44]. These investigators initially described the isolation of Clostridium perfringens type $\mathrm{B}$ from the stool of a young woman, who presented with actively enhancing lesions on her brain MRI and was diagnosed with MS [43]. C. perfringens type B is an epsilon toxin-secreting bacillus that can be found in the stool of ruminant animals; this $29 \mathrm{kDa}$ epsilon toxin in these ruminant animals can cause a devastating enterotoxemia disease in which there is blood brain barrier dysfunction and white matter injury $[44,45]$. These investigators also demonstrated that immunoreactivity to this epsilon toxin is 10 times more prevalent in people with MS than in healthy controls [43], and that the epsilon toxin can bind to mammalian cells via the myelin and lymphocyte protein MAL [44]. Moreover, these investigators have shown that in primary murine CNS cultures, the epsilon toxin binds to and kills mature oligodendrocytes, but not astrocytes, microglia, or neurons [45]. For this epsilon toxin to function as a trigger for MS in humans, colonization of a human host by $C$. perfringens type B would be needed followed by dissemination of this toxin to the bloodstream. Once in the blood stream, this $29 \mathrm{kDa}$ epsilon toxin could reach brain tissue through the third and fourth ventricles via the fenestrated capillaries of the circumventricular organs, which are known to allow direct exchange between the blood and the central nervous system [46]. Conversely, the epsilon toxin could disrupt the blood brain barrier and thus reach brain tissue in a more direct manner. The first of the two possibilities would be consistent with the location of early MS lesions and the progression of these lesions [17,19,20,22].

Another way in which infection could play a role in MS would be a viral infection acting as a trigger for neurodegeneration. This association of Epstein-Barr virus (EBV) with MS was first made when serum antibody titers to EBV were noted in MS patients; the geometric mean titer of antibodies to EBV was significantly higher in MS patients that in controls (107.0 versus 77.1) [47]. This association was further strengthened when Epstein Barr nuclear antigen-1 (EBNA-1) was the target of the oligoclonal bands in the CSF of some MS patients [48]. In 5/15 MS patients, a distinctive oligoclonal band antigen specific banding pattern for EBNA-1 was observed in comparison to $0 / 12$ controls $(\mathrm{P}=0.037$, Fisher's Exact Probability). The presence of intrathecal IgG in the form of oligoclonal bands is seen in the CSF in greater than $90 \%$ of MS patients [49]. Oligoclonal bands are not specific for MS because such bands are also seen in $10 \%$ of patients with other inflammatory diseases of the CNS. In most other diseases in which oligoclonal bands are present in the CSF, the bands represent an antigen-driven immune response to infectious agents [50]. There are a number of ways the EBV might be involved in MS [51-53] For example, EBV may play a role in MS by initially infecting naïve B cells in the tonsils; these latently EBV-infected B cells after replicating in germinal centers may enter the circulation as well as the CNS where they could produce oligoclonal IgG. At the same time, T cells would be targeting EBV-infected B cells in the body and also might target them in the CNS; when present in the CNS, these T cells would produce 
cytokines such as interleukin 2, interferon gamma, and tumor necrosis factor beta. These cytokines in turn would result in demyelination as well as axonal injury [54-57].

Another virus that has been associated with MS is human herpes virus 6 (HHV-6) [58]. Challoner et al. detected by PCR a 341nucleotide fragment that was $99.4 \%$ identical to the major DNA binding protein gene of HHV-6 in greater than 70\% of MS cases and controls suggesting that HHV-6 is a commensal virus of the human brain [58]. HHV-6 expression was determined by immunocytochemistry with monoclonal antibodies; nuclear staining of oligodendrocytes was seen in MS cases, but not in controls [58]. Moreover, nuclear staining was seen around plaque more often than in uninvolved white matter; these observations suggest an association of HHV-6 with the etiology or pathogenesis of MS [58]. Other investigators confirmed this association of HHV-6 with MS [59-66]. Of interest is one report that demonstrated oligoclonal bands in $38 \%$ of MS patients that were reactive to either EBV or HHV-6, suggesting that both viruses may be involved in separate cohorts of MS patients [63]. The role of HHV-6 in the pathogenesis of MS might involve direct infection of oligodenrocytes that could then lead to neurodegeneration with autoimmunity and cytokine production $[65,66]$.

A third group of viruses associated with MS is the human endogenous retroviruses (HERVs) [67,68]. This association began when Perron et al. reported the isolation of a leptomeningeal cell line (LM7) from the CSF of a patient with MS; this cell line was noted to have viral reverse transcriptase activity [69]. Moreover, electron microscopy revealed the presence of viral particles in this LM7 cell line [69]. These investigators then reported isolation of a retrovirus in human monocytes cultured from 18 patients with MS [70]. This group of investigators next used molecular methods to characterize this novel MS-associated retrovirus that had been repeatedly isolated from leptomeningeal cells, post-mortem choroid plexus cells, and EBVimmortalized B cells from MS patients [71]. Other investigators have confirmed the presence of endogenous human retroviruses from patients with MS [72-75], although the exact role of these retroviruses, if any, in the pathogenesis of MS remains unclear. Moreover, it should be noted that endogenous human retroviruses also have been implicated in the pathogenesis of amyotrophic lateral sclerosis (ALS) $[76,77]$. Clearly, the role of endogenous human retroviruses in neurological disorders such as MS and ALS should be further investigated.

Viruses are not the only microbes that have been associated with MS. One of several bacterial pathogens that have been suggested as possible causes of MS is the spirochete [78-80]. The association of spirochetes with MS began in 1925 when Adams et al. inoculated rhesus monkeys with material from MS cases and observed spirochetes in the ventricular fluid of these monkeys several months later [81]. Steiner in 1952 reported spirochetes in plaque from autopsied MS patients [82], while Ichelson in 1957 reported cultivation of spirochetes from spinal fluids from MS patients [83]. Newman et al. repeated the culture method used by Ichelson and found spirochetes in spinal fluid from MS patients, albeit in a lesser percentage (18.5\% versus $78 \%$ ) [84]. The recognition of Lyme arthritis in 1977 [85] and its spirochetal etiology in 1983 [86] was followed by the association of Lyme disease with chronic neurologic abnormalities $[87,88]$ and the detection of Borrelia burgdorferi DNA by PCR in CSF from patients with Lyme neuroborreliosis [89]. Lyme neuroborreliosis has been well characterized in the medical literature [87-91]. Although antibiotic responsive demyelinating neuropathy related to Lyme disease has been described [92], this is the exception and not the rule [93]. Moreover, the finding of reactive Lyme serology in MS patients has not been found to indicate neurologic Lyme disease [94]. Nevertheless, it should be noted that there are different Borrelia species that cause Lyme disease [91]. In the United States, Borrelia burgdorferi and a newly described spirochete species, Borrelia miyamotoi, [92] are known to cause Lyme disease. In Europe, at least 5 Borrelia species are known to cause human infections [91] with at least 3 of these species $(B$. burgdorferi, $B$. afzelii and $B$. garinii) having been identified by PCR in CSF from patients with neuroborreliosis $[95,96]$ and a fourth species, B. bavariensis [97] recently described as a cause of neuroborreliosis [91]. The Lyme Borrelia complex is expanding and the exact role of newer genomic species as human pathogens remains to be determined [98].

The most recent microorganism that has been associated with MS is Chlamydophila pneumoniae [99-105]. In order to appreciate the potential ways in which this intracellular pathogen might play a role in MS, a brief review of the pathophysiology C. pneumoniae is useful. Chlamydia (Chlamydophila) pneumoniae was first described in 1986 as a respiratory pathogen [106] and has since become recognized as an important cause of pneumonia and other respiratory tract infections [107-112]. During chlamydial infection of the human respiratory tract, C. pneumoniae appear to be able to infect polymorphonucelar (PMN) cells and delay the spontaneous apoptosis of these PMN cells [113]. Thus, Chlamydia is able to replicate in these PMN cells and then silently infect and propagate in macrophages [114]. Clearly, apoptotic PMN cells are able to serve as "Trojan horses" for $C$. pneumoniae and allow chlamydial infection to be spread to macrophages as well as to distant tissue sites [115]. This type of systemic dissemination of $C$. pneumoniae via macrophages has been demonstrated in several different types of animal models [116-118]. In particular, $C$. pneumoniae-infected alveolar macrophages in animals or humans are able to transmigrate through the mucosal barrier, and provide Chlamydia with access to the lymphatic circulation as well as the systemic circulation [119-121]. Indeed, there is considerable evidence that this type of monocyte/macrophage-medicated dissemination of $C$. pneumoniae occurs in humans [118,122-128].

Given the observation that $C$. pneumoniae is able to disseminate systemically in white blood cells, the next question that can be asked is how might such dissemination involve the blood brain barrier and the brain itself? In order to answer this question, a review of the choroid plexus and the circumventricular organs is useful. The choroid plexus is a complex epithelial-endothelial vascular interface within the ventricular system of the vertebrate brain [129]. It is comprised of epithelial cells, fenestrated blood vessels, and stoma; the choroid plexus is primarily involved in the production of cerebrospinal fluid (CSF). The circumventricular organs are structures lining the cavity of the third and fourth ventricle and possess a vascular architecture in which their capillaries have a wall devoid of blood-brain barrier [46]. Indeed, the hallmarks of the circumventricular organs are fenestrated capillaries, high permeability, and location around the third and fourth ventricles. This unique arrangement permits direct exchange between the blood and the nervous tissue of these organs. Recently, the circumventricular organs have been considered as a possible entry site for circulating white blood cells into the CSF [130]. Moreover, the fenestrated capillaries of the circumventricular organs are regulated by angiogenesis, which is accompanied by the active proliferation of endothelial cells [131]. Such endothelial cells could be easily infected by transendothelial migration of $C$. pneumoniae from infected 
peripheral blood mononuclear cells as has been demonstrated in an experimental transendothelial migration model [132]. Evidence that this can occur is seen in a report of chlamydial infection of ependymal cells in the ventricular tissues of some patients with multiple sclerosis [133]. These investigators suggest that the circumventricular organs may allow entry of $C$. pneumoniae-infected mononuclear cells into the CNS. Infection of ventricular ependymal cells by $C$. pneumoniae could then lead to cytokine-mediated damage to brain tissue surrounding these ventricles. Moreover, infection of ventricular ependymal cells by C. pneumoniae would explain the visualization by electron microscopy of chlamydial elementary bodies in the CSF of MS patients [133]. Such ventricular infection by Chlamydia would also explain the observations that affinity-driven immunoblot studies have demonstrated reactivity of oligoclonal bands in CSF from MS patients against elementary body antigens of $C$. pneumoniae [134,135]. Finally, ventricular infection by $C$. pneumoniae would explain the presence of chlamydial DNA and mRNA transcripts in CSF from some patients with MS [136,137].

Chlamydiae are known to produce large amounts of heat shock protein 60 (HSP 60) during chronic, persistent infections such as seen in human atheroma [138]; this HSP 60 is thought to play an important role in the pathogenesis of chronic chlamydial infections [139]. Heat shock protein 60 is an evolutionarily conserved protein in both eukaryotes and prokaryotes that is recognized as potent activator of the innate immune system and is capable of inducing the production of proinflammatory cytokines by the monocyte-macrophage system [140-143]. Importantly, human mitochondrial HSP 60 has been proposed as a danger signal of stressed or damaged cells [144]. Both chlamydial HSP 60 and human HSP 60 contribute to inflammation in human atheroma and are able induce inflammation to levels induced by Escherichia coli lipopolysaccharide [144]. Infection of ventricular ependymal cells by $C$. pneumoniae or other pathogens could serve as a focus of HSP 60, which in turn would stress and/or damage neurons and oligodendrocytes resulting in neuronal cell death, axonal injury, loss of oligodendrocytes, and demyelination [145]. Such HSP 60 mediated neurodegeneration and demyelination in the CNS has been described in a murine model in which intrathecal HSP 60 is injected [146]. The fact that neurodegeneration and demyelination in the CNS involves TLR4 and MyD88 confirms that this molecular pathway is able to the release of endogenous TLR ligands from injured CNS cells and is a common process in many different types of brain injury. Indeed, once there a brain injury involving release of HSP 60 has occurred, a vicious cycle can occur due to the activation of microglia, the resident CNS monocyte. Such a cycle involving release of HSP 60 from injured CNS tissue with activation of toll-like receptor 4 has been shown to medicate neurodegeneration in the CNS of mice [147] and has been implicated in multiple sclerosis [148] and myalgic encephalomyelitis [149].

This review of the pathophysiology of multiple sclerosis clearly demonstrates that MS is a wide spread CNS neurodegenerative process that involves white matter, gray matter, and the spinal cord. This neurodegenerative process seen in MS is similar to many other neurologic diseases such as Alzheimer's and Parkinson's diseases, amyotrophic lateral sclerosis, and prion diseases in that it is an inflammatory process [150]. The inflammatory process seen with MS and other neurologic diseases is mediated by HSP 60 from stressed and damaged cells as well as by multiple inflammatory cytokines produced by the immune cells, both local resident cells like activated microglia and by infiltrating immune cells [54]. Hence, this process can be correctly termed an "autoimmune" process. The important role that chlamydial HSP 60 may play as a trigger and human HSP 60 may play as a propagator in this CNS autoimmune process are only now becoming apparent. Because of the numerous ways in which stressed or injured cells in the CNS might contribute to this autoimmune process, it has been difficult to identify a specific "autoreactive target" although HSP 60 might well deserve this designation. Equally difficult is identifying a "trigger" event. A careful review of the medical literature suggests a number of infectious triggers. Of these, Chlamydia pneumoniae is a particularly compelling in that this pathogen could play an important role in several different ways. One way would be involvement in the development of chronic cerebrospinal venous insufficiency as recently described [151]. Another way would be through infection of the ependymal cells of the ventricles where the production of HSP 60 could serve as an inflammatory triggering as described in this commentary. Clearly, the choroid plexus is now recognized as an important component of MS $[152,153]$. Other toxins or pathogens could enter the CNS via the choroid plexus/ circumventricular organs and/or infect these CNS tissues. Indeed, equally compelling reports in the medical literature strongly suggest that MS is an infectious syndrome with a number of different ways that infection may play a role [103].

Regardless of which infectious triggers may be involved, MS should be considered to be an infectious syndrome that involves a neurodegenerative process resulting in an autoimmune disease. Identification of each potential infectious trigger described in this review early in the course of MS might allow appropriate antimicrobial intervention as has been done with at least one of these triggers, $C$. pneumoniae [154]. Future studies in MS should identify each of these potential infectious triggers early in the course of MS. Such identification might then allow appropriate antimicrobial therapy. Moreover, stratification of MS based on specific infectious triggers would allow specific clinical trials that are focused on each pathogen.

\section{References}

1. Noseworthy JH, Lucchinetti C, Rodriguez M, Weinshenker BG (2000) Multiple sclerosis. N Engl J Med 343: 938-952.

2. Compston A, Coles A (2008) Multiple sclerosis. Lancet 372: 1502-1517.

3. Nylander A, Hafler DA (2012) Multiple sclerosis. J Clin Invest 122: 1180-1188.

4. (2013) Atlas of MS 2013: Mapping multiple sclereosis around the world. London: Multiple Sclerosis International Federation.

5. Evans C, Beland SG, Kulaga S, Wolfson C, Kingwell E, et al. (2013) Incidence and prevalence of multiple sclerosis in the Americas: $\mathrm{A}$ systematic review. Neuroepidemiology 40: 195-210.

6. Kingwell E, Marriott JJ, Jetté N, Pringsheim T, Makhani N, et al. (2013) Incidence and prevalence of multiple sclerosis in Europe: A systematic review. BMC Neurol 13: 128.

7. Bishop M, Rumrill PD (2015) Multiple sclerosis: Etiology, symptoms, incidence and prevalence and implications for community living and employment. Work 52: 725-734.

8. Smith KJ, McDonald WI (1999) The pathophysiology of multiple sclerosis: The mechanisms underlying the production of symptoms and the natural history of the disease. Philos Trans R Soc Lond B Biol Sci 354: 1649-1673.

9. Janssens AC, de Boer JB, van Doorn PA, van ver Ploeg HM, van ver Meché FG, et al. (2003) Expectations of wheelchair-dependency in recently diagnosed patients with multiple sclerosis and their partners. Eur J Neurol 10: 287-293.

10. Hawton AJ, Green C (2016) Multiple sclerosis: Relapses, resource use and costs. Eur J Health Econ 17: 875-884. 
11. Lassmann H, van Horssen J, Mahad D (2012) Progressive multiple sclerosis: Pathology and pathogenesis. Nat Rev Neurol 8: 647-656.

12. Lassmann H (2013) Pathology and disease mechanisms in different stages of multiple sclerosis. J Neurol Sci 333: 1-4.

13. Dendrou CA, Fugger L, Friese MA (2015) Immunopathology of multiple sclerosis. Nat Rev Immunol 15: 545-558.

14. Charcot J (1848) Histologie de la sclerose en plaques. Gazette Hosp Civ Mil 41: 554-566.

15. Dawson JW (1916) The histology of multiple sclerosis. Trans R Soc Edinburgh 50: 517-740.

16. Fazekas F, Barkhof F, Filippi M, Grossman RI, Li DK, et al. (1999) The contribution of magnetic resonance imaging to the diagnosis of multiple sclerosis. Neurology 53: 448-456.

17. Barnett MH, Prineas JW (2004) Relapsing and remitting multiple sclerosis: Pathology of the newly forming lesion. Ann Neurol 55: 458-468.

18. Barnett MH, Sutton I (2006) The pathology of multiple sclerosis: a paradigm shift. Curr Opin Neurol 19: 242-247.

19. Frohman EM, Racke MK, Raine CS (2006) Multiple sclerosis--the plaque and its pathogenesis. $\mathrm{N}$ Engl J Med 354: 942-955.

20. Henderson AP, Barnett MH, Parratt JD, Prineas JW (2009) Multiple sclerosis: Distribution of inflammatory cells in newly forming lesions. Ann Neurol 66: 739-753.

21. Prineas JW, Kwon EE, Cho ES, Sharer LR (1984) Continual breakdown and regeneration of myelin in progressive multiple sclerosis plaques. Ann N Y Acad Sci 436: 11-32.

22. Prineas JW, Parratt JD (2012) Oligodendrocytes and the early multiple sclerosis lesion. Ann Neurol 72: 18-31.

23. Barnett MH, Henderson AP, Prineas JW (2006) The macrophage in MS: Just a scavenger after all? Pathology and pathogenesis of the acute MS lesion. Mult Scler 12: 121-132.

24. Lucchinetti C, Brück W, Parisi J, Scheithauer B, Rodriguez M, et al. (2000) Heterogeneity of multiple sclerosis lesions: implications for the pathogenesis of demyelination. Ann Neurol 47: 707-717.

25. Metz I, Weigand SD, Popescu BF, Frischer JM, Parisi JE, et al. (2014) Pathologic heterogeneity persists in early active multiple sclerosis lesions. Ann Neurol 75: 728-738.

26. Frischer JM, Weigand SD, Guo Y, Kale N, Parisi JE, et al. (2015) Clinical and pathological insights into the dynamic nature of the white matter multiple sclerosis plaque. Ann Neurol 78: 710-721.

27. Gay D, Esiri M (1991) Blood-brain barrier damage in acute multiple sclerosis plaques. An immunocytological study. Brain 114: 557-572.

28. Cramer SP, Modvig S, Simonsen HJ, Frederiksen JL, Larsson HB (2015) Permeability of the blood-brain barrier predicts conversion from optic neuritis to multiple sclerosis. Brain 138: 2571-2583.

29. Frischer JM, Bramow S, Dal-Bianco A, Lucchinetti CF, Rauschka H, et al (2009) The relation between inflammation and neurodegeneration in multiple sclerosis brains. Brain 132: 1175-1189.

30. Popescu BF, Lucchinetti CF (2012) Pathology of demyelinating diseases. Annu Rev Pathol 7: 185-217.

31. Calabrese M, Filippi M, Gallo P (2010) Cortical lesions in multiple sclerosis. Nat Rev Neurol 6: 438-444.

32. Charcot JM (1877) Lectures on the diseases of the nervous System. (Vol 1) New Sydenham Society; London, pp: 157-202.

33. Prins M, Schul E, Geurts J, van der Valk P, Drukarch B, et al. (2015) Pathological differences between white and grey matter multiple sclerosis lesions. Ann N Y Acad Sci 1351: 99-113.

34. Peterson JW, Bö L, Mörk S, Chang A, Trapp BD (2001) Transected neurites, apoptotic neurons and reduced inflammation in cortical multiple sclerosis lesions. Ann Neurol 50: 389-400.

35. van Horssen J, Brink BP, de Vries HE, van der Valk P, Bø L (2007) The blood-brain barrier in cortical multiple sclerosis lesions. J Neuropathol Exp Neurol 66: 321-328.

36. Jürgens T, Jafari M, Kreutzfeldt M, Bahn E, Brück W, et al. (2016) Reconstruction of single cortical projection neurons reveals primary spine loss in multiple sclerosis. Brain 139: 39-46.
37. Kreutzfeldt M, Bergthaler A, Fernandez M, Brück W, Steinbach K, et al. (2013) Neuroprotective intervention by interferon- $\hat{I}^{3}$ blockade prevents CD8+ T cell-mediated dendrite and synapse loss. J Exp Med 210: 2087-2103.

38. Yang G, Parkhurst CN, Hayes S, Gan WB (2013) Peripheral elevation of TNF-alpha leads to early synaptic abnormalities in the mouse somatosensory cortex in experimental autoimmune encephalomyelitis. Proc Natl Acad Sci 110: 10306-10311.

39. Michailidou I, Willems JG, Kooi EJ, van Eden C, et al. (2015) Complement C1q-C3-associated synaptic changes in multiple sclerosis hippocampus. Ann Neurol 77: 1007-1026.

40. Magliozzi R, Howell OW, Reeves C, Roncaroli F, Nicholas R, et al. (2010) A Gradient of neuronal loss and meningeal inflammation in multiple sclerosis. Ann Neurol 68: 477-493.

41. Flügel A, Schläger C, Lühder F, Odoardi F (2011) Autoimmune disease in the brain--how to spot the culprits and how to keep them in check. J Neurol Sci 311 Suppl 1: S3-11.

42. Bittner S, Wiendl H (2016) Neuroimmunotherapies targeting T cells: From pathophysiology to therapeutic applications. Neurotherapeutics 13: 4-19.

43. Rumah KR, Linden J, Fischetti VA, Vartanian T (2013) Isolation of Clostridium perfringens Type $\mathrm{B}$ in an individual at first clinical presentation of multiple sclerosis provides clues for environmental triggers of the disease. PLoS One 8: e76359.

44. Rumah KR, Ma Y, Linden JR, Oo ML, Anrather J, et al. (2015) The myelin and lymphocyte protein MAL is required for binding and activity of Clostridium perfringens $\hat{\mathrm{I}} \mu$-toxin. PLoS Pathog 11: e1004896.

45. Linden JR, Ma Y, Zhao B, Harris JM, Rumah KR, et al. (2015) Clostridium perfringens epsilon toxin causes selective death of mature oligodenrocytes and central nervous system demyelination. MBio 6: e02513.

46. Duvernoy HM, Risold PY (2007) The circumventricular organs: an atlas of comparative anatomy and vascularization. Brain Res Rev 56: 119-147.

47. Sumaya CV, Myers LW, Ellison GW (1980) Epstein-Barr virus antibodies in multiple sclerosis. Arch Neurol 37: 94-96.

48. Rand KH, Houck H, Denslow ND, Heilman KM (2000) Epstein-Barr virus nuclear antigen-1 (EBNA-1) associated oligoclonal bands in patients with multiple sclerosis. J Neurol Sci 173: 32-39.

49. Thompson EJ, Freedman MS (2006) Cerebrospinal fluid analysis in the diagnosis of multiple sclerosis. Adv Neurol 98: 147-160.

50. Smith-Jensen T, Burgoon MP, Anthony J, Kraus H, Gilden DH, et al. (2000) Comparison of immunoglobulin G heavy-chain sequences in MS and SSPE brains reveals an antigen-driven response. Neurology 28: 1227-1232.

51. Pender MP (2011) The essential role of Epstein-Barr virus in the pathogenesis of multiple sclerosis. Neuroscientist 17: 351-367.

52. Pender MP, Burrows SR (2014) Epstein-Barr virus and multiple sclerosis: Potential opportunities for immunotherapy. Clin Transl Immunology 3 : e27.

53. Fernández-Menéndez S, Fernández-Morán M, Fernández-Vega I, PérezÁlvarez A, Villafani-Echazú J (2016) Epstein-Barr virus and multiple sclerosis. From evidence to therapeutic strategies. J Neurol Sci 361: 213-219.

54. Zindler E, Zipp F (2010) Neuronal injury in chronic CNS inflammation. Best Pract Res Clin Anaesthesiol 24: 551-562.

55. di Penta A, Moreno B, Reix S, Fernandez-Diez B, Villanueva M, et al. (2013) Oxidative stress and proinflammatory cytokines contribute to demyelination and axonal damage in a cerebellar culture model of neuroinflammation. PLoS One 8: e54722.

56. Bsibsi M, Peferoen LA, Holtman IR, Nacken PJ, Gerritsen WH, et al. (2014) Demyelination during multiple sclerosis is associated with combined activation of microglia/macrophages by IFN- $\hat{I}^{3}$ and alpha Bcrystallin. Acta Neuropathol 128: 215-229. 
57. Ransohoff RM, Schafer D, Vincent A, Blachère NE, Bar-Or A (2015) Neuroinflammation: Ways in which the immune system affects the brain. Neurotherapeutics 12: 896-909.

58. Challoner PB, Smith KT, Parker JD, MacLeod DL, Coulter SN, et al. (1995) Plaque-associated expression of human herpesvirus 6 in multiple sclerosis. Proc Natl Acad Sci U S A 92: 7440-7444.

59. Soldan SS, Berti R, Salem N, Secchiero P, Flamand L, et al. (1997) Association of human herpes virus 6 (HHV-6) with multiple sclerosis: Increased IgM response to HHV-6 early antigen and detection of serum HHV-6 DNA. Nat Med 3: 1394-1397.

60. Ahlqvist J, Fotheringham J, Akhyani N, Yao K, Fogdell-Hahn A, et al. (2005) Differential tropism of human herpes virus 6 (HHV-6) variants and induction of latency by HHV-6A in oligodendrocytes. J Neurovirol 11: 384-394.

61. Derfuss T, Hohlfeld R, Meinl E (2005) Intrathecal antibody (IgG) production against human herpes virus type 6 occurs in about $20 \%$ of multiple sclerosis patients and might be linked to a polyspecific B-cell response. J Neurol 252: 968-971.

62. Virtanen JO, Pietilainen-Nicklen J, Uotila L, Färkkilä M, Vaheri A, et al. (2011) Intrathecal human herpes virus 6 antibodies in multiple sclerosis and other demyelination diseases presenting as oligoclonal bands in cerebrospinal fluid. J Neuroimmunol 237: 93-97.

63. Virtanen JO, Wohler J, Fenton K, Reich DS, Jacobson S (2014) Oligoclonal bands in multiple sclerosis reactive against two herpes viruses and association the magnetic resonance imaging findings. Mult Scler 20: 27-34.

64. Pietiläinen-Nicklén J, Virtanen JO, Uotila L, Salonen O, Färkkilä M, et al. (2014) HHV-6-positivity in diseases with demyelination. J Clin Virol 61: 216-219.

65. Leibovitch EC, Jacobson S (2014) Evidence linking HHV-6 with multiple sclerosis: An update. Curr Opin Virol 9: 127-133.

66. Fotheringham J, Jacobson S (2005) Human herpes virus 6 and multiple sclerosis: Potential mechanisms for virus-induced disease. Herpes 12: 4-9.

67. Fujinami RS, Libbey JE (1999) Endogenous retroviruses: Are they the cause of multiple sclerosis? Trends in Microbiol 7: 263-264.

68. Anthony JM, Deslauriers AM, Bhat RK, Ellestad KK, Power C (2011) Human endogenous retroviruses and multiple sclerosis: Innocent bystanders or disease determinants? Biochem Biophys Acta 1812 162-176.

69. Perron H, Geny C, Laurent A, Mouriquand C, Pellat J, et al. (1989) Leptomeningeal cell line from multiple sclerosis with reverse transcriptase activity and viral particles. Res Virol 140: 551-561.

70. Perron H, Lalande B, Gratacap B, Laurent A, Genoulaz O, et al. (1991) Isolation of retrovirus from patients with multiple sclerosis. Lancet 337 862-863.

71. Perron H, Garson JA, Bedin F, Beseme F, Paranhos-Baccala G, et al. (1997) Molecular identification of novel retrovirus repeatedly isolated from patients with multiple sclerosis. The Collaborative Research Group on Multiple Sclerosis. Proc Natl Acad Sci U S A 94: 7583-7588.

72. Haahr S, Sommerlund M, Christensen T, Jensen AW, Hansen HJ, et al. (1994) A putative new retrovirus associated with multiple sclerosis and the possible involvement of Epstein-Barr virus in this disease. Ann N Y Acad Sci 724: 148-156.

73. Christensen T, Jensen AW, Munch M, Haahr S, Sørensen PD, et al. (1997) Characterization of retroviruses from patients with multiple sclerosis. Acta Neurol Scand Suppl 169: 49-58.

74. Christensen T, Dissing Sørensen P, Riemann H, Hansen HJ, Munch M, et al. (2000) Molecular characterization of HERV-H variants associated with multiple sclerosis. Acta Neurol Scand 101: 229-238.

75. Nexø BA, Christensen T, Frederiksen J, Møller-Larsen A, Oturai AB, et al. (2011) The etiology of multiple sclerosis: Genetic evidence for the involvement of the human endogenous retrovirus HERV-Fcl. PLoS One 6: e16652.
76. Laska MJ, Brudek T, Nissen KK, Christensen T, Møller-Larsen A, et al. (2012) Expression of HERV-Fc1, a human endogenous retrovirus, is increased in patients with active multiple sclerosis. J Virol 86: 3713-3722.

77. Douville R, Liu J, Rothstein J, Nath A (2011) Identification of active loci of a human endogenous retrovirus in neurons of patients with amyotrophic lateral sclerosis. Ann Neurol 69: 141-151.

78. Li W, Lee MH, Henderson L, Tyagi R, Bachani M, et al. (2015) Human endogenous retrovirus- $\mathrm{K}$ contributes to motor neuron disease. Sci Transl Med 7: 307ra153.

79. Steiner G (1952) Acute plaques in multiple sclerosis, their pathogenic significance and the role of spirochetes as etiological factor. J Neuropath Exp Neurol 11: 343-372.

80. Gay D, Dick G (1986) Spirochaetes, lyme disease and multiple sclerosis. Lancet 2: 685.

81. Marshall V (1988) Multiple sclerosis is a chronic central nervous system infection by a spirochetal agent. Med Hypotheses 25: 89-92.

82. Adams DK, Blacklock JWS, McCluskie JAW (1925) Spirochetes in ventricular fluid of monkeys inoculated from cases of disseminated sclerosis. J Path Bacteriol 28: 117-118.

83. Ichelson RR (1957) Cultivation of spirochaetes from spinal fluids of multiple sclerosis cases and negative controls. Proc Soc Exp Biol Med 95: 57-58.

84. Newman HW, Purdy C, Rantz L, Hill FC (1958) The spirochete and multiple sclerosis. Calif Med 89: 387-389.

85. Steere AC, Malawista SE, Snydman DR, Shope RE, Andiman WA, et al. (1977) Lyme arthritis: An epidemic of oligoarticular arthritis in children and adults in three Connecticut communities. Arthritis Rheum 20: 7-17.

86. Steere AC, Grodzicki RL, Kornblatt AN, Craft JE, Barbour AG, et al. (1983) The spirochetal etiology of Lyme disease. N Engl J Med 308: 733-740.

87. Reik L, Steere AC, Bartenhagen NH, Shope RE, Malawista SE, et al. (1979) Neurologic abnormalities of Lyme disease. Medicine (Baltimore) 58: 281-294.

88. Logigian EL, Kaplan RF, Steere AC (1990) Chronic neurologic manifestations of Lyme disease. N Engl J Med 323: 1438-1444.

89. Nocton JJ, Bloom BJ, Rutledge BJ, Persing DH, Logigian EL, et al. (1996) Detection of Borrelia burgdorferi DNA by polymerase chain reaction in cerebrospinal fluid in Lyme neuroborreliosis. J Infect Dis 174: 623-627.

90. Halperin JJ (2015) Nervous system Lyme disease. Infect Dis Clin North Am 29: 241-253.

91. Koedel U, Fingerle V, Pfister HW (2015) Lyme neuroborreliosisepidemiology, diagnosis and management. Nat Rev Neurol 11: 446-456.

92. Muley SA, Parry GJ (2009) Antibiotic responsive demyelinating neuropathy related to Lyme disease. Neurology 72: 1786-1787.

93. Agosta F, Rocca MA, Benedetti B, Capra R, Cordioli C, et al. (2006) MR imaging assessment of brain and cervical cord damage in patients with neuroborreliosis. AJNR Am J Neuroradiol 27: 892-894.

94. Coyle PK, Krupp LB, Doscher C (1993) Significance of reactive Lyme serology in multiple sclerosis. Ann Neurol 34: 745-747.

95. Pritt BS, Mead PS, Johnson DK, Neitzel DF, Respicio-Kingry LB, et al. (2016) Identification of a novel pathogenic Borrelia species causing Lyme borreliosis with unusually high spirochaetaemia: A descriptive study. The Lancet Infectious Diseases 16: 556-564.

96. Ornstein K, Berglund J, Bergstrom S, Norrby R, Barbour AG (2002) Three major Lyme Borrelia genospecies (Borrelia burgdorferi sensu stricto, B. afzelii and $B$. garinii) identified by PCR in cerebrospinal fluid from patients with neuroborreliosis in Sweden. Scand J Infect Dis 34: 341-346.

97. Margos G, Wilske B, Sing A, Hizo-Teufel C, Cao WC, et al. (2013) Borrelia bavariensis sp. nov. is widely distributed in Europe and Asia. Int J Syst Evol Microbiol 63: 4284-4288.

98. Stanek G, Reiter M (2011) The expanding Lyme Borrelia complex-clinical significance of genomic species? Clin Microbiol Infect 17: 487-493. 
99. Sriram S, Stratton CW, Yao S, Tharp A, Ding L, et al. (1999) Chlamydia pneumoniae infection of the central nervous system in multiple sclerosis. Ann Neurol 46: 6-14.

100. Yao SY, Stratton CW, Mitchell WM, Sriram S (2001) CSF oligoclonal bands in MS include antibodies against Chlamydophila antigens. Neurology 56: 1168-1176.

101. Dong-Si T, Weber J, Liu YB, Buhmann C, Bauer H, et al. (2004) Increased prevalence of and gene transcription by Chlamydia pneumoniae in cerebrospinal fluid of patients with relapsing-remitting multiple sclerosis. J Neurol 251: 542-547.

102. Contini C, Seraceni S, Castellazzi M, Granieri E, Fainardi E (2008) Chlamydophila pneumoniae DNA and mRNA transcript levels in peripheral blood mononuclear cells and cerebrospinal fluid of patients with multiple sclerosis. Neurosci Res 62: 58-61.

103. Stratton CW, Wheldon DB (2006) Multiple sclerosis: An infectious syndrome involving Chlamydophila pneumoniae. Trends Microbiol 14: 474-479.

104. Fainardi E, Castellazzi M, Seraceni S, Granieri E, Contini C, et al. (2008) Under the microscope: Focus on Chlamydia pneumoniae infection and multiple sclerosis. Curr Neurovasc Res 5: 60-70.

105. Ivanova MV, Kolkova NI, Morgunova EY, Pashko YP, Zigangirova NA, et al. (2015) Role of Chlamydia in multiple sclerosis. Bull Exp Biol Med 159: 646-648.

106. Grayston JT, Kuo CC, Wang SP, Altman J (1986) A new Chlamydia psittaci strain, TWAR, isolated in acute respiratory tract infections. $\mathrm{N}$ Engl J Med 315: 161-168.

107. Grayston JT, Wang SP, Kuo CC, Campbell LA (1989) Current knowledge on Chlamydia pneumoniae, strain TWAR, an important cause of pneumonia and other acute respiratory diseases. Eur J Clin Microbiol Infect Dis 8: 191-202.

108. Grayston JT, Campbell LA, Kuo CC, Mordhorst CH, Saikku P, et al. (1990) A new respiratory tract pathogen: Chlamydia pneumoniae strain TWAR. J Infect Dis 161: 618-625.

109. Grayston JT (1992) Chlamydia pneumoniae, strain TWAR pneumonia Annu Rev Med 43: 317-323.

110. Grayston JT (1992) Infections caused by Chlamydia pneumoniae strain TWAR. Clin Infect Dis 15: 757-763.

111. Kuo CC, Jackson LA, Campbell LA, Grayston JT (1995) Chlamydia pneumoniae (TWAR). Clin Microbiol Rev 8: 451-461.

112. Burillo A, Bouza E (2010) Chlamydophila pneumoniae. Infect Dis Clin North Am 24: 61-71.

113. van Zandbergen G, Gieffers J, Kothe H, Rupp J, Bollinger A, et al. (2004) Chlamydia pneumoniae multiply in neutrophil granulocytes and delay their spontaneous apoptosis. J Immunol 172: 1768-1776.

114. Rupp J, Pfleiderer L, Jugert C, Moeller S, Klinger M, et al. (2009) Chlamydia pneumoniae hides inside apoptotic neutrophils to silently infect and propagate in macrophages. PLoS One 4: e6020.

115. Laskay T, van Zandbergen G, Solbach W (2008) Neutrophil granulocytes as host cells and transport vehicles for intracellular pathogens: Apoptosis as infection-promoting factor. Immunobiology 213: 183-191.

116. Moazed TC, Kuo CC, Grayston JT, Campbell LA (1998) Evidence of systemic dissemination of Chlamydia pneumoniae via macrophages in the mouse. J Infect Dis 177: 1322-1325.

117. Bodetti TJ, Timms P (2000) Detection of Chlamydia pneumoniae DNA and antigen in the circulating mononuclear cell fractions of humans and koalas. Infect Immun 68: 2744-2747.

118. Gieffers J, van Zandbergen G, Rupp J, Sayk F, Krüger S, et al. (2004) Phagocytes transmit Chlamydia pneumoniae from the lungs to the vasculature. Eur Respir J 23: 506-510.

119. Airenne S, Surcel HM, Alakärppä H, Laitinen K, Paavonen J, et al. (1999) Chlamydia pneumoniae infection in human monocytes. Infect Immun 67: 1445-1449.

120. Blasi F, Centanni S, Allegra L (2004) Chlamydia pneumoniae: Crossing the barriers? Eur Respir J 23: 499-500.
121. Herweg JA, Rudel T (2016) Interaction of Chlamydiae with human macrophages. FEBS J 283: 608-618.

122. Redecke V, Dalhoff K, Bohnet S, Braun J, Maass M (1998) Interaction of Chlamydia pneumoniae and human alveolar macrophages: Infection and inflammatory response. Am J Respir Cell Mol Biol 19: 721-727.

123. Boman J, Söderberg S, Forsberg J, Birgander LS, Allard A, et al. (1998) High prevalence of Chlamydia pneumoniae DNA in peripheral blood mononuclear cells in patients with cardiovascular disease and in middleaged blood donors. J Infect Dis 178: 274-277.

124. Blasi F, Boman J, Esposito G, Melissano G, Chiesa R, et al. (1999) Chlamydia pneumoniae DNA detection in peripheral blood mononuclear cells is predictive of vascular infection. J Infect Dis 180: 2074-2076.

125. Boman J, Gaydos CA (2000) Polymerase chain reaction detection of Chlamydia pneumoniae in circulating white blood cells. J Infect Dis 181 Suppl 3: S452-454.

126. Yamaguchi H, Yamada M, Uruma T, Kanamori M, Goto H, et al. (2004) Prevalence of viable Chlamydia pneumoniae in peripheral blood mononuclear cells of healthy blood donors. Transfusion 44: 1072-1078.

127. Cirino F, Webley WC, West C, Croteau NL, Andrzejewski C, et al. (2006) Detection of Chlamydia in the peripheral blood cells of normal donors using in vitro culture, immunofluorescence microscopy and flow cytometry techniques. BMC Infect Dis 6: 23.

128. Witte L, Droemann D, Dalhoff K, Rupp J (2011) Chlamydia pneumoniae is frequently detected in the blood after acute lung infection. Eur Respir J 37: 712-714.

129. Wolburg H, Paulus W (2010) Choroid plexus: Biology and pathology. Acta Neuropathol 119: 75-88.

130. Schulz M, Engelhardt B (2005) The circumventricular organs participate in the immunopathogenesis of experimental autoimmune encephalomyelitis. Cerebrospinal Fluid Res 30: 2: 8.

131. Miyata S (2015) New aspects in fenestrated capillary and tissue dynamics in the sensory circumventricular organs of adult brains. Front Neurosci 9: 390.

132. Rupp J, Koch M, van Zandbergen G, Solbach W, Brandt E, et al. (2005) Transmission of Chlamydia pneumoniae infection from blood monocytes to vascular cells in a novel transendothelial migration model. FEMS Microbiol Lett 242: 203-208.

133. Sriram S, Ljunggren-Rose A, Yao SY, Whetsell WO (2005) Detection of chlamydial bodies and antigens in the central nervous system of patients with multiple sclerosis. J Infect Dis 192: 1219-1228.

134. Yao SY, Stratton CW, Mitchell WM, Sriram S (2001) CSF oligoclonal bands in MS include antibodies against Chlamydophila antigens. Neurology 56: 1168-1176.

135. Fainardi E, Castellazzi M, Tamborino C, Seraceni S, Tola MR, et al. (2009) Chlamydia pneumoniae-specific intrathecal oligoclonal antibody response is predominantly detected in a subset of multiple sclerosis patients with progressive forms. J Neurovirol 15: 425-433.

136. Dong-Si T, Weber J, Liu YB, Buhmann C, Bauer H, et al. (2004) Increased prevalence of and gene transcription by Chlamydia pneumoniae in cerebrospinal fluid in patients with relapsing-remitting multiple sclerosis. J Neurol 251: 542-547.

137. Contini C, Seraceni S, Castellazzi M, Granieri E, Fainardi E (2008) Chlamydophila pneumoniae DNA and mRNA transcript levels in peripheral blood mononuclear cells and cerebrospinal fluid of patients with multiple sclerosis. Neurosci Res 62: 58-61.

138. Kol A, Sukhova GK, Lichtman AH, Libby P (1998) Chlamydial heat shock protein 60 localizes in human atheroma and regulates macrophage tumor necrosis factor-alpha and matrix metalloproteinase expression. Circulation 98: 300-307.

139. Stephens RS (2003) The cellular paradigm of chlamydial pathogenesis. Trends Microbiol 11: 44-51.

140. Tsan MF, Gao B (2004) Cytokine function of heat shock proteins. Am J Physiol Cell Physiol 286: C739-744.

141. Tsan MF, Gao B (2004) Heat shock protein and innate immunity. Cell Mol Immunol 1: 274-279. 
Citation: Stratton CW (2016) A Review of Multiple Sclerosis as an Infectious Syndrome. J Neurol Neurophysiol 7: 400. doi: 10.4172/2155-9562.1000400

Page 8 of 8

142. Habich C, Burkart V (2007) Heat shock protein 60: regulatory role on innate immune cells. Cell Mol Life Sci 64: 742-751.

143. Henderson B, Fares MA, Lund PA (2013) Chaperonin 60: A paradoxical, evolutionarily conserved protein family with multiple moonlighting functions. Biol Rev Camb Philos Soc 88: 955-987.

144. Cappello F, de Macario EC, Zummo G, Macario AJ (2011) Immunohistochemistry of human Hsp60 in health and disease: From autoimmunity to cancer. Methods Mol Biol 787: 245-254.

145. Kol A, Bourcier T, Lichtman AH, Libby P (1999) Chlamydial and human heat shock protein 60 s activate human vascular endothelium, smooth muscle cells and macrophages. J Clin Infest 103: 571-577.

146. Rosenberger K, Dembny P, Derkow K, Engel O, Krüger C, et al. (2015) Intrathecal heat shock protein 60 mediates neurodegeneration and demyelination in the CNS through a TLR4- and MyD88-dependent pathway. Mol Neurodegener 10: 5 .

147. Lehnardt S, Schott E, Trimbuch T, Laubisch D, Krueger C, et al. (2008) A vicious cycle involving release of heat shock protein 60 from injured cells and activation of toll-like receptor 4 mediates neurodegeneration in the CNS. J Neurosci 28: 2320-2331.

148. Prabhakar S, Kurien E, Gupta RS, Zielinski S, Freedman MS (1994) Heat shock protein immunoreactivity in CSF: correlation with oligoclonal banding and demyelinating disease. Neurology 44: 1644-1648.
149. Elfaitouri A, Herrmann B, Bölin-Wiener A, Wang Y, Gottfries CG, et al. (2013) Epitopes of microbial and human heat shock protein 60 and their recognition in myalgic encephalomyelitis. PLoS One 8: e81155.

150. Amor S, Peferoen LA, Vogel DY, Breur M, van der Valk P, et al. (2014) Inflammation in neurodegenerative diseases--an update. Immunology 142: 151-166.

151. Contini C, Granieri E, Fainardi E, Stratton CW (2015) Role of Chlamydophila pneumoniae in the pathogenesis of chronic venous insufficiency in patients with multiple sclerosis. J Mult Scler 2: 150.

152. Schwartz M, Baruch K (2014) The resolution of neuroinflammation in neurodegeneration: Leukocyte recruitment via the choroid plexus. EMBO J 33: 7-22.

153. Kooij G, de Vries HE (2015) The best basic science paper in multiple sclerosis in 2014: Important role for the choroid plexus in the central nervous system entry of leukocytes. Mult Scler J 21:372-373.

154. Sriram S, Mitchell W, Stratton C (1998) Multiple sclerosis associated with Chlamydia pneumoniae infection of the CNS. Neurology 50: 571-572. 